\title{
Amiodarone versus lidocaine and placebo for the prevention of ventricular fibrillation after aortic crossclamping: A randomized, double-blind, placebo-controlled trial
}

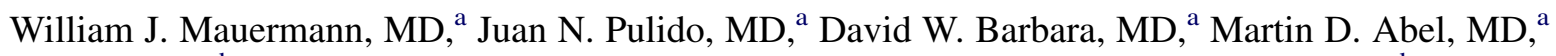 \\ Zhuo Li, MS, ${ }^{\mathrm{b}}$ Laurie A. Meade, RN, ${ }^{\mathrm{a}}$ Hartzell V. Schaff, MD, ${ }^{\mathrm{c}}$ and Roger D. White, $\mathrm{MD}^{\mathrm{d}}$
}

\begin{abstract}
Objective: Ventricular fibrillation occurs commonly after aortic crossclamping in patients undergoing cardiac surgery. Ventricular fibrillation increases myocardial oxygen consumption, and defibrillation may harm the myocardium. Thus, a pharmacologic approach to decreasing the incidence of ventricular fibrillation or the number of shocks required may be beneficial. The goal of this study was to evaluate whether amiodarone or lidocaine was superior to placebo for the prevention of ventricular fibrillation after aortic crossclamping in patients undergoing a variety of cardiac surgical procedures.
\end{abstract}

\begin{abstract}
Methods: Patients undergoing cardiac surgery requiring aortic crossclamping were randomized to receive lidocaine $1.5 \mathrm{mg} / \mathrm{kg}$, amiodarone $300 \mathrm{mg}$, or placebo before aortic crossclamp removal The primary outcomes were the incidence of ventricular fibrillation and the number of shocks required to terminate ventricular fibrillation.

Results: A total of 342 patients completed the trial. On multivariate analysis, there was no difference in the incidence of ventricular fibrillation among treatment groups. The number of required shocks was categorized as 0 , 1 to 3 , and greater than 3 . On multivariate analysis, patients receiving amiodarone required fewer shocks to terminate ventricular fibrillation (odds ratio, $0.51 ; 95 \%$ confidence interval, $0.31-0.83 ; P=.008$ vs placebo). There was no difference between lidocaine and placebo in the number of required shocks (odds ratio, $0.86 ; 95 \%$ confidence interval, $0.52-1.41 ; P=.541)$.
\end{abstract}

Conclusions: In patients undergoing a variety of cardiac surgical procedures, neither amiodarone nor lidocaine reduced the incidence of ventricular fibrillation. Amiodarone decreased the number of shocks required to terminate ventricular fibrillation. (J Thorac Cardiovasc Surg 2012;144:1229-34)

The incidence of ventricular fibrillation (VF) after release of the aortic crossclamp in patients undergoing cardiac surgery has been reported to be between $45 \%$ and $100 \% .^{1-7}$ Multiple mechanisms have been proposed to explain the high incidence of VF, including ischemia-mediated increases in reentry, automaticity, and reperfusion injury. ${ }^{8-10}$ VF may result in increased myocardial oxygen consumption, distension of the ventricle with resultant increases in wall tension, and acidosis of the myocardial tissue. ${ }^{11-14}$ These changes may be particularly pronounced in the hypertrophied ventricle when the mean arterial blood pressure is less than 50 to $60 \mathrm{~mm} \mathrm{Hg}{ }^{15-17}$

\footnotetext{
From the Department of Anesthesiology, ${ }^{a}$ Department of Biomedical Statistics and Informatics, ${ }^{\mathrm{b}}$ Department of Cardiovascular Surgery, ${ }^{\mathrm{c}}$ and Department of Anesthesiology and Internal Medicine, ${ }^{\mathrm{d}}$ Mayo Clinic, Rochester, Minn.

Clinical Trials.gov Identifier: NCT00587483

Funding from the Departments of Anesthesiology and Cardiovascular Surgery at the Mayo Clinic was used for this study.

Disclosures: Authors have nothing to disclose with regard to commercial support.

Received for publication Sept 19, 2011; revisions received Feb 13, 2012; accepted for publication June 15, 2012; available ahead of print July 6, 2012.

Address for reprints: William J. Mauermann, MD, 200 First St SW, Mary Brigh

2-752, Rochester, MN 55902 (E-mail: Mauermann.william@mayo.edu). $0022-5223 / \$ 36.00$

Copyright (C) 2012 by The American Association for Thoracic Surgery

http://dx.doi.org/10.1016/j.jtcvs.2012.06.039
}

Although VF is known to adversely affect the heart, the "gold standard" treatment, internal direct-current shock, also may be harmful. Animal models using monophasic damped sine waveform shocks suggest that defibrillation leads to decreased myocardial performance and microscopic damage to myocytes and that the injury is more pronounced with repeated shocks with a short time interval between shocks. ${ }^{18,19}$ Given these findings, the prevention of reperfusion VF or a decrease in the number of defibrillation attempts required to terminate $\mathrm{VF}$ may be of benefit in preserving myocardial function after cardiopulmonary bypass (CPB).

Lidocaine, a class I (sodium channel blocking) antiarrhythmic drug, has a long history of use in cardiac surgery for the prevention of VF. Several studies have shown its efficacy in preventing VF and decreasing the number of shocks required to defibrillate VF when it does occur. ${ }^{1-5,20}$ However, all of these studies have been performed in relatively homogeneous patient populations, that is, patients undergoing coronary artery bypass grafting (CABG). Intravenous amiodarone has multiple mechanisms of action, including blockade of potassium, sodium, and calcium channels, as well as alpha and beta adrenergic antagonism. ${ }^{21}$ Amiodarone has been well studied in the setting of out-of-hospital cardiac arrest. Randomized, blinded 


$$
\begin{aligned}
& \text { Abbreviations and Acronyms } \\
& \begin{aligned}
\text { CABG } & =\text { coronary artery bypass grafting } \\
\text { CI } & =\text { confidence interval } \\
\text { CPB } & =\text { cardiopulmonary bypass } \\
\text { OR } & =\text { odds ratio } \\
\text { VF } & =\text { ventricular fibrillation }
\end{aligned}
\end{aligned}
$$

trials in adults have shown amiodarone to be superior to both placebo and lidocaine in the resuscitation of patients with $\mathrm{VF}$ or pulseless ventricular tachycardia. ${ }^{22,23}$ Other studies have shown amiodarone to improve the response of VF to shocks. ${ }^{24,25}$ To date, 2 studies have evaluated amiodarone for the prevention of $\mathrm{VF}$ after aortic crossclamping with mixed results. ${ }^{1,6}$

The goal of the present study was to evaluate whether amiodarone or lidocaine was superior to placebo for the prevention of VF after aortic crossclamping in patients undergoing a variety of cardiac surgical procedures.

\section{MATERIALS AND METHODS}

This randomized, double-blind, placebo-controlled trial was conducted at Mayo Clinic in Rochester, Minnesota. The study was approved by the Mayo Foundation Institutional Review Board, and all patients gave written, informed consent. Patients were eligible for inclusion if they were aged more than 18 years and undergoing an elective cardiac procedure that was expected to include crossclamping of the aorta. Women of childbearing age were included only if they agreed to the use of birth control for at least 5 months after the procedure. Patients were excluded for an allergy to amiodarone or a history of organ dysfunction due to previous amiodarone use. Patients were also excluded if it was expected that they would require more than mild systemic hypothermia $\left(<32^{\circ} \mathrm{C}\right)$ during $\mathrm{CPB}$. Before operation, subjects were randomized in a 1:1:1 fashion to receive amiodarone (group A), lidocaine hydrochloride (group L), or saline (group P) before aortic crossclamp removal. All study drugs were prepared by a research pharmacist and diluted to $12 \mathrm{~mL}$ total volume. Anesthesiologists, surgeons, and $\mathrm{CPB}$ perfusionists were strictly blinded as to the content of the syringes.

\section{Procedure}

After consent was obtained and randomization had occurred, patients were brought to the operating room. Induction and maintenance of anesthesia were at the discretion of the anesthesiologist and included the use of midazolam, sodium thiopental, propofol or ketamine, fentanyl or sufentanil, isoflurane, and pancuronium or vecuronium. Hemodynamic monitoring included the use of an arterial catheter and central venous catheter with or with or without a pulmonary artery catheter.

The cannulation sites for $\mathrm{CPB}$ were at the discretion of the cardiac surgeon and dependent on the operation. The aorta was cannulated with a patient size-appropriate cannula. Venous cannulation was obtained with a single 2-stage cannula in the right atrium or separate cannulae in the superior and inferior vena cavae. Anticoagulation was initiated with $300 \mathrm{u} / \mathrm{kg}$ of heparin and maintained according to an activated clotting time (Hemochron 801, International Technidyne, Edison, NJ) of more than $500 \mathrm{sec}-$ onds. Perfusion during CPB used nonpulsatile flow with Sarns 9000 (Terumo Cardiovascular Systems, Ann Arbor, Mich) or Sorin S5 (Sorin, Munich, Germany) CPB equipment and a Terumo membrane oxygenator. CPB flows were maintained at 2.0 to $2.4 \mathrm{~L} \cdot \mathrm{min}^{-1} \cdot \mathrm{m}^{-2}$. Mean arterial pressure was maintained at 60 to $80 \mathrm{~mm} \mathrm{Hg}$ during CPB. Hyperkalemic cold blood cardioplegia was given every 20 to 30 minutes for myocardial protection (Table 1). Cardioplegia consisted of blood mixed with crystalloid components in a ratio of 4 parts blood to 1 part crystalloid. The crystalloid component consisted of lactated Ringer's solution with $50 \mathrm{mEq} / \mathrm{L}$ of sodium bicarbonate and either $100 \mathrm{mEq} / \mathrm{L}$ (for induction of cardiac arrest) or $50 \mathrm{mEq} / \mathrm{L}$ (for maintenance of cardiac arrest) of potassium. Warm, potassium-free restorative cardioplegia was not administered before crossclamp removal. Septal myocardial temperature readings as a marker of adequacy of cardioplegia delivery were not used.

The surgeon notified the anesthesia and perfusion teams before anticipated removal of the aortic crossclamp with a goal of administering the study drugs approximately 3 minutes ( 3 circulation times) before crossclamp removal. At this time, patients in group A received $300 \mathrm{mg}$ of amiodarone, patients in group $\mathrm{L}$ received $1.5 \mathrm{mg} / \mathrm{kg}$ of lidocaine, and patients in group P received placebo (saline). All study drugs were administered via the $\mathrm{CPB}$ venous reservoir. Patients were not given magnesium sulfate during the study period because of potential confounding effects.

If VF occurred after aortic crossclamp removal, patients received up to 3 consecutive rectilinear biphasic waveform shocks using internal paddles with $10 \mathrm{~J}$ of energy (Zoll R Series Defibrillator, Zoll Medical, Chelmsford, Mass). If defibrillation was unsuccessful after 3 attempts using $10 \mathrm{~J}$, a second dose of study medication was administered on the basis of prior randomization. Patients in group A received an additional $150 \mathrm{mg}$ of amiodarone, patients in group $\mathrm{L}$ received $1.5 \mathrm{mg} / \mathrm{kg}$ of lidocaine, and patients in group P received placebo (saline). Defibrillation was again attempted, but escalating energy levels were used (first shock $10 \mathrm{~J}$, second shock $20 \mathrm{~J}$, and third shock $30 \mathrm{~J}$ ). As a safety measure, the patient's randomization was made immediately available to the team in the operating room after the second dose of medication. The patient's group assignment was noted on paper and delivered in a sealed, opaque envelope with the study drugs to the operating room. Thus, should VF persist after the second dose of study medication and second set of shocks, the envelope could be immediately opened and the entire team would be aware of what medications had already been administered. At this point, further therapy was at the discretion of the consultant anesthesiologist and surgeon.

\section{Outcome Measurements}

Patient demographics were recorded and included age, medical comorbidities, current medication use, left ventricular ejection fraction, type of operation, duration of $\mathrm{CPB}$, duration of aortic crossclamping, and times of cardioplegia administration. Two primary outcomes were compared among the 3 study groups: (1) the incidence of VF after removal of the aortic crossclamp and (2) the number of defibrillations required to terminate VF.

In addition, we sought to determine the relationship between left ventricular mass and the incidence of VF after aortic crossclamp removal. To this end, the patients' charts were manually reviewed by a single, blinded investigator and recorded left ventricular mass as obtained from a transthoracic echocardiogram performed at the Mayo Clinic within 1 year of operation.

\section{Sample Size}

On the basis of the available literature, the expected overall incidence of $\mathrm{VF}$ after removal of the aortic crossclamp is approximately $70 \%$. By using a chi-square test with $80 \%$ power and an alpha of 0.0167 to adjust for multiple comparisons (given the total of 3 comparisons, $0.05 / 3=0.0167$ was used in the calculation.), we estimated that we would need 113 patients in each group to show a $30 \%$ reduction in the incidence of VF with amiodarone. Given the potential for patient dropouts, we planned to enroll 120 patients in each group for a total study population of 360 patients.

\section{Statistical Methods}

All data including primary and secondary outcome data were analyzed on the basis of the intention to treat principle. Categoric baseline characteristics and outcomes were compared between groups using chi-square tests or 
TABLE 1. Demographics

\begin{tabular}{|c|c|c|c|c|}
\hline & $\begin{array}{l}\text { Control } \\
n=112\end{array}$ & $\begin{array}{c}\text { Lidocaine } \\
\mathrm{n}=115\end{array}$ & $\begin{array}{c}\text { Amiodarone } \\
\mathrm{n}=115\end{array}$ & $\begin{array}{c}P \\
\text { value }\end{array}$ \\
\hline Age (y) & $63.6 \pm 13.0$ & $62.7 \pm 13.9$ & $63.3 \pm 13.6$ & 91 \\
\hline Height $(\mathrm{cm})$ & $174 \pm 10.2$ & $172.9 \pm 10.2$ & $171 \pm 10.2$ & .039 \\
\hline Weight $(\mathrm{kg})$ & $91.2 \pm 20.8$ & $88.1 \pm 19.5$ & $86.9 \pm 18.4$ & .429 \\
\hline \multicolumn{5}{|l|}{ Gender } \\
\hline Male & $82(73.2 \%)$ & $81(70.4 \%)$ & $74(64.3 \%)$ & \multirow[t]{2}{*}{.333} \\
\hline Female & $30(26.8 \%)$ & $34(29.6 \%)$ & $41(35.7 \%)$ & \\
\hline Left ventricular ejection fraction $(\%)$ & $62.8 \pm 11.7$ & $62.7 \pm 11.5$ & $62.7 \pm 10.8$ & .862 \\
\hline \multicolumn{5}{|l|}{ Procedure } \\
\hline CABG only & $20(17.9 \%)$ & $15(13.0 \%)$ & $18(15.7 \%)$ & \multirow[t]{4}{*}{.806} \\
\hline Valve only & $31(27.7 \%)$ & $37(32.2 \%)$ & $38(33.0 \%)$ & \\
\hline Septal myectomy & $34(30.4 \%)$ & $30(26.1 \%)$ & $34(29.6 \%)$ & \\
\hline Multiple procedures & $27(24.1 \%)$ & $33(28.7 \%)$ & $25(21.7 \%)$ & \\
\hline \multicolumn{5}{|l|}{ Medical history } \\
\hline Diabetes mellitus & $14(12.5 \%)$ & $14(12.2 \%)$ & $16(13.9 \%)$ & .916 \\
\hline Coronary artery disease & $45(40.2 \%)$ & $41(35.7 \%)$ & $42(36.5 \%)$ & 757 \\
\hline Current smoker & $9(8.0 \%)$ & $11(9.6 \%)$ & $7(6.1 \%)$ & .618 \\
\hline COPD & $5(4.5 \%)$ & $7(6.1 \%)$ & $3(2.6 \%)$ & 436 \\
\hline Hypertension & $48(42.9 \%)$ & $37(32.2 \%)$ & $55(47.8 \%)$ & .048 \\
\hline \multicolumn{5}{|l|}{ History of dysrhythmias } \\
\hline Atrial fibrillation & $17(15.2 \%)$ & $22(19.1 \%)$ & $23(20.0 \%)$ & .605 \\
\hline Atrial flutter & $1(0.89 \%)$ & $2(1.7(\%)$ & $4(3.5 \%)$ & .373 \\
\hline Ventricular & $3(2.7 \%)$ & $3(2.6 \%)$ & $0(0 \%)$ & .213 \\
\hline \multicolumn{5}{|l|}{ Preoperative medications } \\
\hline Beta-blocker & $73(65.2 \%)$ & $73(63.5 \%)$ & $67(58.3 \%)$ & .532 \\
\hline ACEI/ARB & $29(25.9 \%)$ & $31(27.0 \%)$ & $43(37.4 \%)$ & .112 \\
\hline Statin & $60(53.6 \%)$ & $42(36.5 \%)$ & $46(40.0 \%)$ & .024 \\
\hline Digoxin & $7(6.3 \%)$ & $4(3.5 \%)$ & $7(6.1 \%)$ & .574 \\
\hline Amiodarone & $2(1.8 \%)$ & $7(6.1 \%)$ & $5(4.3 \%)$ & .259 \\
\hline Duration of aortic crossclamp (min) & $53.3 \pm 36.8$ & $46.5 \pm 56.1$ & $47.4 \pm 32.1$ & .447 \\
\hline Duration of CPB (min) & $78.0 \pm 48.7$ & $74.3 \pm 40.0$ & $70.8 \pm 64.0$ & .444 \\
\hline Time between cardioplegia administrations (min) & $21.0 \pm 9.1$ & $20.8 \pm 8.9$ & $21.4 \pm 9.3$ & .956 \\
\hline Time from study drug administration to crossclamp removal (min) & $3.2 \pm 7.6$ & $3.0 \pm 5.6$ & $3.6 \pm 5.4$ & 415 \\
\hline
\end{tabular}

Data are presented as mean \pm standard deviation for continuous variables and n (\%) for categoric variables. $C A B G$, Coronary artery bypass grafting; $C O P D$, chronic obstructive pulmonary disease; $A C E I$, angiotensin-converting enzyme inhibitor; $A R B$, angiotensin receptor blocker; $C P B$, cardiopulmonary bypass.

Fisher exact test (where appropriate), whereas continuous variables were compared using analysis of variance or Kruskal-Wallis tests (where appropriate). Because a few baseline variables were significantly different between groups (Table 1), normal and ordinal logistic regression models were used to find univariate and multivariate predictors for VF and number of shocks. Then, the variable containing the treatment groups was forced in each multivariate model to detect the difference after adjusting for confounding variables. The multivariable model considered all univariately significant variables $(P<.05)$ with model selection using the stepwise method (backward and forward methods resulted in the same model). All statistical tests were 2 -sided with the alpha level set at 0.05 for statistical significance.

\section{RESULTS}

A total of 360 patients were enrolled in the trial. Eighteen patients were excluded after enrollment for protocol violations, leaving 115 patients in group A, 115 patients in group $\mathrm{L}$, and 112 patients in group $\mathrm{P}$ (Figure 1). A comparison of patient and procedural characteristics between study groups is shown in Table 1. Patients in group A were more likely to have hypertension $(47.8 \%$ vs $32.2 \%$ in group $\mathrm{L}$ and $42.9 \%$ in group $\mathrm{P} ; \mathrm{P}=.048$ ) and patients in group $\mathrm{P}$ were more likely to be taking a statin medication at the time of surgery (53.6\% vs $36.5 \%$ in group $\mathrm{L}$ and $40.0 \%$ in group $\mathrm{A}$; $P=.024)$. The mean left ventricular ejection fraction was normal. Eighteen patients had ejection fractions less than $40 \%$, and these were evenly distributed between study groups $(P=.221)$ (data not shown).

In total, 196 patients $(57.3 \%)$ experienced $\mathrm{VF}$ after aortic crossclamp removal. The only univariate predictor of $\mathrm{VF}$ was operation type, with patients undergoing septal myectomy having a higher incidence of VF than patients undergoing CABG (odds ratio [OR], 5.09; 95\% confidence interval $[\mathrm{CI}], 2.47-10.47 ; P<.001$ ) (Table 2). In contrast, advancing age, preoperative digoxin or amiodarone use, and longer aortic crossclamp and CPB times reduced the occurrence of VF. When univariate predictors were placed in a multivariate model, septal myectomy (OR, 5.59; 95\% CI, 


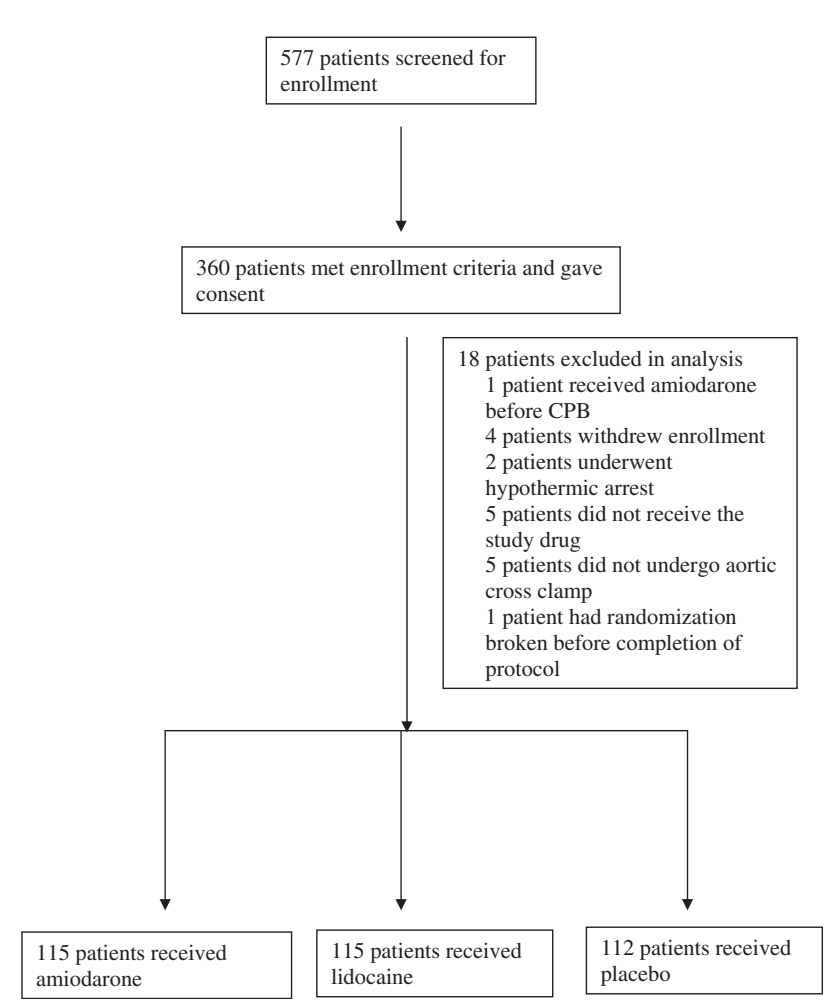

FIGURE 1. Flow diagram of patient enrollment and dropouts. $C P B$, Cardiopulmonary bypass.

$2.69-11.26 ; P<.001)$ and valve surgery (OR, $2.12 ; 95 \% \mathrm{CI}$, $1.07-4.19 ; P=.031)$ became positive predictors of VF. Preoperative amiodarone use was protective against VF (OR, $0.24 ; 95 \%$ CI $0.07-0.82 ; P=.023$ ) (Table 3). There was no effect of acute administration of amiodarone or lidocaine on the occurrence of VF.

TABLE 2. Univariate analysis of incidence of ventricular fibrillation after aortic crossclamp removal and number of shocks required to terminate ventricular fibrillation

\begin{tabular}{|c|c|c|c|}
\hline Category & OR & $95 \% \mathrm{CI}$ & $\begin{array}{c}P \\
\text { value }\end{array}$ \\
\hline \multicolumn{4}{|c|}{ Incidence of VF after crossclamp remooval } \\
\hline Amiodarone vs placebo & 0.65 & $0.39-1.11$ & .117 \\
\hline Lidocaine vs placebo & 0.80 & $0.47-1.37$ & .433 \\
\hline \multicolumn{4}{|l|}{ Type of operation } \\
\hline Valve vs CABG & 1.92 & $0.98-3.77$ & .058 \\
\hline Myectomy vs CABG & 5.09 & $2.47-10.47$ & $<.001$ \\
\hline Multiple procedures vs $\mathrm{CABG}$ & 1.86 & $0.92-3.74$ & .083 \\
\hline \multicolumn{4}{|l|}{ No. of shocks required } \\
\hline Amiodarone vs placebo & 0.51 & $0.32-0.84$ & .008 \\
\hline Lidocaine vs placebo & 0.82 & $0.52-1.33$ & .424 \\
\hline \multicolumn{4}{|l|}{ Type of operation } \\
\hline Valve vs CABG & 1.97 & $1.03-3.76$ & .040 \\
\hline Myectomy vs CABG & 3.87 & $2.00-7.50$ & $<.001$ \\
\hline Multiple procedures vs $\mathrm{CABG}$ & 1.83 & $0.93-3.58$ & .078 \\
\hline
\end{tabular}

TABLE 3. Multivariate analysis of incidence of ventricular fibrillation

\begin{tabular}{lccr}
\hline & OR & $\mathbf{9 5} \% \mathbf{C I}$ & $\begin{array}{r}\boldsymbol{P} \\
\text { value }\end{array}$ \\
\hline Amiodarone vs placebo & 0.65 & $0.37-1.12$ & .121 \\
Lidocaine vs placebo & 0.85 & $0.48-1.47$ & .577 \\
Type of operation & & & \\
$\quad$ Valve only vs CABG & 2.12 & $1.07-4.19$ & .031 \\
$\quad$ Septal myectomy vs CABG & 5.59 & $2.69-11.26$ & $<.001$ \\
$\quad$ Multiple procedures vs CABG & 1.98 & $0.97-4.01$ & .059 \\
Preoperative amiodarone use & 0.24 & $0.07-0.82$ & .023 \\
\hline OR, Odds ratio; $C I$, confidence interval; $C A B G$, coronary artery bypass grafting.
\end{tabular}

For the outcome of the number of shocks required to terminate VF, patients were categorized as receiving 0,1 to 3 , or more than 3 shocks. We chose to categorize the number of shocks because the number of shocks did not follow normal distribution with $75 \%$ of patients requiring 2 or fewer shocks. Univariate predictors of patients requiring fewer shocks included receiving amiodarone versus placebo, older age, preoperative use of amiodarone or digoxin, and longer duration of CPB. Univariate predictors of patients requiring a larger number of shocks included septal myectomy versus $\mathrm{CABG}$ and valve surgery versus $\mathrm{CABG}$ (Table 2). In the multivariate model predicting the number of shocks required to terminate VF, amiodarone was superior placebo (OR, $0.51 ; 95 \% \mathrm{CI}, 0.31-0.83 ; P=.008)$. Lidocaine provided no benefit in reducing the number of shocks required to terminate VF (OR, $0.86 ; 95 \% \mathrm{CI}$, $0.52-1.41 ; P=.541$ ). Predictors of an increased number of shocks required included valve surgery versus $\mathrm{CABG}$, septal myectomy versus CABG, and multiple combined procedures versus CABG (Table 4). Preoperative amiodarone use decreased the number of shocks required to terminate VF (OR, 0.24; 95\% CI, 0.07-0.79; $P=.019$ ).

We did attempt a subgroup analysis based on the type of operation. Patients were divided into groups consisting of isolated CABG $(\mathrm{N}=53)$, valve surgery $(\mathrm{N}=106)$, septal myectomy $(\mathrm{N}=98)$, and combined procedures $(\mathrm{N}=85)$. In this subgroup analysis, neither lidocaine nor amiodarone decreased the incidence of VF or the number of shocks

TABLE 4. Multivariate analysis of number of defibrillations (categorized into $0,1-3$, and $>3$ )

\begin{tabular}{lccr}
\hline & OR & $\mathbf{9 5} \% \mathbf{C I}$ & $\begin{array}{c}\boldsymbol{P} \\
\text { value }\end{array}$ \\
\hline Amiodarone vs placebo & 0.51 & $0.31-0.83$ & .008 \\
Lidocaine vs placebo & 0.86 & $0.52-1.41$ & .541 \\
$\begin{array}{l}\text { Type of operation } \\
\quad \text { Valve vs CABG }\end{array}$ & & & \\
$\quad$ Septal myectomy vs CABG & 3.13 & $1.11-4.09$ & .024 \\
$\quad$ Multiple procedures vs CABG & 2.03 & $1.98-7.35$ & $<.001$ \\
Preoperative digoxin use & 0.39 & $0.14-1.10$ & .038 \\
Preoperative amiodarone use & 0.24 & $0.07-0.79$ & .075 \\
\hline
\end{tabular}

$O R$, Odds ratio; $C I$, confidence interval; $C A B G$, coronary artery bypass grafting. 
required to terminate $\mathrm{VF}$ in the specific subsets of patients (data not shown).

Given the relationship between patients undergoing septal myectomy and the high incidence of VF, we analyzed the effect of left ventricular mass on the incidence of VF. A total of 230 patients had undergone transthoracic echocardiography within 1 year before operation. Left ventricular mass was recorded from the available echocardiography reports. After adjusting for significant predictors that were found to affect VF and the need for defibrillatory shocks among the whole cohort, increasing left ventricular mass was predictive of VF after aortic crossclamp removal (OR, 1.04; CI, $1.01-1.08 ; P=.009$ for every $10-\mathrm{g}$ increase in left ventricular mass) and the need for increasing number of defibrillatory shocks (OR, 1.05; CI, 1.02-1.08; $P<.001$ for every 10 -g increase in left ventricular mass). Given the fact that left ventricular mass was available for only 230 of the 342 patients in the study population, left ventricular mass was not used in the final multivariate models.

\section{DISCUSSION}

In this trial of patients undergoing a variety of cardiac surgical procedures, neither amiodarone nor lidocaine given $3 \mathrm{~min}$ utes before aortic crossclamp removal decreased the incidence of VF. However, amiodarone, but not lidocaine, decreased the number of shocks required to terminate VF.

Several studies have shown lidocaine to decrease the incidence of reperfusion VF when compared with control groups. ${ }^{1-3,5,6}$ All of these studies were performed in patients undergoing CABG. Thus, the current trial differs from these studies in that we included a variety of surgical procedures, including CABG, valve surgery, septal myectomy for the treatment of hypertrophic obstructive cardiomyopathy, and combined procedures. Our study also differed from previous studies in terms of lidocaine dosing. Two of the previous studies used doses of $100 \mathrm{mg}$ of lidocaine, ${ }^{1,2} 2$ studies used doses of $200 \mathrm{mg}$ of lidocaine, ${ }^{5,6}$ and 1 study administered $2 \mathrm{mg} / \mathrm{kg}$ of lidocaine. ${ }^{3}$ The current study used $1.5 \mathrm{mg} / \mathrm{kg}$ of lidocaine as the initial treatment dose. Given that the mean weight of the patients in the lidocaine group was $88.1 \mathrm{~kg}$, the mean dose of lidocaine administered would have been $132.2 \mathrm{mg}$. This dose would have been within the dosing limits reported by other investigators to be successful.

Two studies have investigated the use of amiodarone to prevent VF after aortic crossclamp removal in cardiac surgery. Samantaray and colleagues ${ }^{6}$ randomized 34 patients undergoing CABG to receive $150 \mathrm{mg}$ of amiodarone or placebo before aortic crossclamp removal. The incidence of VF in the amiodarone group was $18 \%$ versus $65 \%$ in the placebo group $(P=.01)$. In a larger trial, Ayoub and colleagues ${ }^{1}$ randomized 120 patients undergoing $C A B G$ to receive $150 \mathrm{mg}$ amiodarone, $100 \mathrm{mg}$ lidocaine, or placebo 2 minutes before removal of the aortic crossclamp. These investigators found the incidence of VF to be higher in the groups receiving amiodarone or placebo versus the group receiving lidocaine ( $48 \%$ vs $45 \%$ vs $20 \%$ respectively, $P=.031$ ). However, they found the energy required to terminate VF was lower in the patients receiving amiodarone versus the controls ( $16 \pm 7 \mathrm{~J}$ vs $25 \pm 8 \mathrm{~J} ; P=.023$ ).

The dose of amiodarone used in this study was significantly higher than the dose used in the 2 previous investigations (300 vs $150 \mathrm{mg}){ }^{1,6}$ We selected this dose on the basis of the large volume of distribution of amiodarone and the expected hemodilution in the $\mathrm{CPB}$ reservoir. Even with this larger dose, we were unable to replicate the decrease in VF found by Samantaray and colleagues. ${ }^{6}$ Our results were similar to those of Ayoub and colleagues, ${ }^{1}$ who found no difference in the incidence of VF, but that VF was more easily terminated in patients receiving amiodarone.

Our study differs from the described investigations. ${ }^{1,6}$ Most important, we included a heterogeneous group of operations, including open cardiac chamber procedures. The fact that patients undergoing valve operations or septal myectomy had both a higher incidence of $\mathrm{VF}$ and required a higher number of shocks to terminate VF (Tables 3 and 4) suggests that in addition to the proarrhythmic effects of myocardial ischemia and reperfusion, gaseous air emboli from open-chamber procedures and preexisting myocardial hypertrophy are likely important mediators of VF after aortic crossclamp removal in cardiac surgery. A subgroup analysis of left ventricular mass showed that increasing left ventricular mass likely plays an important role in the development of VF and the success of defibrillatory shocks. The finding that left ventricular mass is a strong predictor of VF and increases the number of shocks required to terminate VF is important and may warrant further research. Unfortunately, this was a secondary finding in our study, and the data were obtained retrospectively. In addition, less than $70 \%$ of the study patients had echocardiographic data available for review. These reasons precluded the use of left ventricular mass in our statistical modeling. The fact that this trial included patients undergoing a variety of surgical procedures in a large, tertiary care cardiac surgery practice makes our results applicable to diverse cardiac surgical practice and not just that of patients undergoing isolated CABG.

In addition, our dosing of amiodarone was higher than that in previous investigations. However, this may not have been a large enough dose given the large volume of distribution of amiodarone combined with hemodilution from the CPB reservoir. Although the numbers are small (14 total patients), patients who were taking amiodarone preoperatively had a significantly decreased incidence of $\mathrm{VF}$ and required fewer shocks to terminate VF. The numbers are small and the results must be viewed with caution, but they suggest that an intravenous bolus of $300 \mathrm{mg}$ of amiodarone may not be adequate to achieve therapeutic 
tissue levels in the myocardium. Future studies aimed at preventing reperfusion VF may focus on preoperative loading of patients with oral amiodarone.

It seems paradoxical that our univariate analyses indicate that older patients and longer CPB and crossclamp times seem to be protective against VF. This is a reflection of the type of operation. The patients undergoing myectomy were younger and have short $\mathrm{CPB}$ and crossclamp times compared with patients undergoing CABG. However, our data show that septal myectomy is a strong predictor of reperfusion VF. Thus, it is the operation type and not the age, or CPB and crossclamp duration, that predicts VF. That is why older age and longer CPB and crossclamp times were protective from VF in univariate but not multivariate models.

\section{Study Limitations}

The current trial has some limitations. Despite enrolling a heterogeneous surgical population, the mean left ventricular ejection fraction was normal. Thus, it is unclear whether our results are applicable to patients with decreased left ventricular function. Second, as noted earlier, the dose of administered amiodarone may not have been high enough to achieve therapeutic tissue levels given the added circulatory volume of the CPB circuit. Last, the study population included a large number of patients undergoing septal myectomy for hypertrophic obstructive cardiomyopathy. This may be an uncommon patient population for many cardiac surgical centers.

\section{CONCLUSIONS}

When applied to patients undergoing a variety of cardiac surgical procedures, neither $300 \mathrm{mg}$ of amiodarone nor 1.5 $\mathrm{mg} / \mathrm{kg}$ of lidocaine administered 3 minutes before aortic crossclamp removal decreases the incidence of VF. However, amiodarone, but not lidocaine, reduces the number of shocks required to terminate $\mathrm{VF}$ after aortic crossclamp removal.

\section{References}

1. Ayoub CM, Sfeir PM, Bou-Khalil P, Azar M, Haddadin AS, Harfouch D, et al. Prophylactic amiodarone versus lidocaine for prevention of reperfusion ventricular fibrillation after release of aortic cross-clamp. Eur J Anaesthesiol. 2009;26: 1056-60.

2. Baraka A, Kawkabani N, Dabbous A, Nawfal M. Lidocaine for prevention of reperfusion ventricular fibrillation after release of aortic cross-clamping. J Cardiothorac Vasc Anesth. 2000;14:531-3.

3. Fall SM, Burton NA, Graeber GM, Head HD, Lough FC, Albus RA, et al. Prevention of ventricular fibrillation after myocardial revascularization. Ann Thorac Surg. 1987;43:182-4.

4. Fiore AC, Naunheim KS, Taub J, Braun P, McBride LR, Pennington DG, et al. Myocardial preservation using lidocaine blood cardioplegia. Ann Thorac Surg. 1990;50:771-5.
5. Praeger PI, Kay RH, Moggio R, Somberg E, Pooley R, Sarabu M, et al. Prevention of ventricular fibrillation after aortic declamping during cardiac surgery. Tex Heart Inst J. 1988;15:98-101.

6. Samantaray A, Chandra A, Panigrahi S. Amiodarone for the prevention of reperfusion ventricular fibrillation. J Cardiothorac Vasc Anesth. 2010;24: 239-43.

7. Sellevold OF, Berg EM, Levang OW. Procaine is effective for minimizing postischemic ventricular fibrillation in cardiac surgery. Anesth Analg. 1995;81: 932-8.

8. Hearse DJ. Reperfusion of the ischemic myocardium. J Mol Cell Cardiol. 1977; 9:605-16.

9. Kaplinsky E, Ogawa S, Michelson EL, Dreifus LS. Instantaneous and delayed ventricular arrhythmias after reperfusion of acutely ischemic myocardium: evidence for multiple mechanisms. Circulation. 1981;63:333-40.

10. Murdock DK, Loeb JM, Euler DE, Randall WC. Electrophysiology of coronary reperfusion. A mechanism for reperfusion arrhythmias. Circulation. 1980;61: 175-82.

11. Buckberg GD, Hottenrott CE. Ventricular fibrillation. Its effect on myocardial flow, distribution, and performance. Ann Thorac Surg. 1975;20:76-85.

12. Hottenrott C, Maloney JV Jr, Buckberg G. Studies of the effects of ventricular fibrillation on the adequacy of regional myocardial flow. 3. Mechanisms of ischemia. J Thorac Cardiovasc Surg. 1974;68:634-45.

13. Khuri SF, Marston WA, Josa M, Braunwald NS, Cavanaugh AC, Hunt H, et al. Observations on 100 patients with continuous intraoperative monitoring of intramyocardial $\mathrm{pH}$. The adverse effects of ventricular fibrillation and reperfusion. $J$ Thorac Cardiovasc Surg. 1985;89:170-82.

14. Lockerman ZS, Rose DM, Cunningham JN Jr, Lichstein E. Reperfusion ventricular fibrillation during coronary artery bypass operations and its association with postoperative enzyme release. J Thorac Cardiovasc Surg. 1987;93:247-52.

15. Brazier JR, Cooper N, McConnell DH, Buckberg GD. Studies of the effects of hypothermia on regional myocardial blood flow and metabolism during cardiopulmonary bypass. III. Effects of temperature, time, and perfusion pressure in fibrillating hearts. J Thorac Cardiovasc Surg. 1977;73:102-9.

16. Cox JL, Anderson RW, Pass HI, Currie WD, Roe CR, Mikat E, et al. The safety of induced ventricular fibrillation during cardiopulmonary bypass in nonhypertrophied hearts. J Thorac Cardiovasc Surg. 1977;74:423-32.

17. Spadaro J, Bing OH, Gaasch WH, Laraia P, Franklin A, Weintraub RM. Effects of perfusion pressure on myocardial performance, metabolism, wall thickness, and compliance: comparison of the beating and fibrillating heart. $J$ Thorac Cardiovasc Surg. 1982;84:398-405.

18. Doherty PW, McLaughlin PR, Billingham M, Kernoff R, Goris ML, Harrison DC. Cardiac damage produced by direct current countershock applied to the heart. Am J Cardiol. 1979;43:225-32.

19. Yamaguchi H, Weil M, Tang W, Kamohara T, Jin X, Bisera J. Myocardial dysfunction after electrical defibrillation. Resuscitation. 2002;54:289-96.

20. Kirlangitis J, Middaugh R, Knight R, Goglin W, Helsel R, Grishkin B, et al. Comparison of bretylium and lidocaine in the prevention of ventricular fibrillation after aortic cross-clamp release in coronary artery bypass surgery. $J$ Cardiothorac Anesth. 1990;4:582-7.

21. Sarkozy A, Dorian P. Strategies for reversing shock-resistant ventricular fibrillation. Curr Opin Crit Care. 2003;9:189-93.

22. Dorian P, Cass D, Schwartz B, Cooper R, Gelaznikas R, Barr A. Amiodarone as compared with lidocaine for shock-resistant ventricular fibrillation. $N$ Engl J Med. 2002;346:884-90.

23. Kudenchuk PJ, Cobb LA, Copass MK, Cummins RO, Doherty AM, Fahrenbruch CE, et al. Amiodarone for resuscitation after out-of-hospital cardiac arrest due to ventricular fibrillation. $N$ Engl J Med. 1999;341:871-8.

24. Levine JH, Massumi A, Scheinman MM, Winkle RA, Platia EV, Chilson DA, et al. Intravenous amiodarone for recurrent sustained hypotensive ventricular tachyarrhythmias. Intravenous Amiodarone Multicenter Trial Group. J Am Coll Cardiol. 1996;27:67-75.

25. Petrovic T, Adnet F, Lapandry C. Successful resuscitation of ventricular fibrillation after low-dose amiodarone. Ann Emerg Med. 1998;32:518-9. 